\title{
SIMULATION TESTS OF PELLETING PROCESS IN ASPECT OF OBTAINED STRESSES, CONTACT PRESSURE AND FATIGUE STRENGTH FOR GRANULATOR FLAT DIE
}

\author{
J. Chojnacki $^{*}$, P. Kaldunski ${ }^{* *}$, S. Nagnajewicz ${ }^{* * *}$, R. Patyk ${ }^{\dagger}$
}

\begin{abstract}
Paper presents simulation studies of the pelleting process in aspect of obtained pressures in the contact zone of pelletized material and die. This is an important issue from the point of view of the die construction (to determine the durability of the dies) as well as for the operation process (minimization of the machine's power). In this work, the Finite Element Method and implicit methods for integrating the object motion equation have been used to modelling the pelleting process. Results obtained from the simulation should be treated as an aid in the process of constructing pellet dies.
\end{abstract}

Keywords: pelleting process, fatigue analysis, FEM, numerical analysis

\section{Introduction}

Pelleting is used in various branches of the economy (foundry industry, plastics processing, agriculture, forestry, etc.). Depending on the purpose and type of granular material, various machines and their various constructions are used. Recently, there is of great interest of the pellets production as a heating material belonging to the group of biofuels, where energy is obtained from the combustion of renewable raw materials subjected to granulation. Constructions of the pelleting machines have many basic differences, which concern mainly to the shape of dies: flat or ring, but also other solutions of granulators. However, in each case the die is an integral part of the machine (Fig. 1a), which is subjected to cyclic quite high mechanical loads (sometimes even impact loads), which can lead to its damage (Fig. 1b). In flat die designs, there are several characteristic construction parameters that determine the quality of the pellets obtained and the machine's power demand. Include: hole geometry, die block clearance factor and compression ratio (Buchely et al., 2016). The term hole geometry is to be understood to mean the diameter of the hole and the way the holes are arranged on the die, while the die block gauge is the ratio of the area of the holes to the work surface of the die. The increase in the clearance coefficient causes a reduction of the power demand in the pelleting process, but at the same time causes a decrease in the quality of the obtained pellet. The compression ratio is defined as the ratio of the die hole lengths to their diameter (Tie-Li Ye et al., 2012). Depending on the required pellet quality and the type of pelleted material, it can take different values (Zdanowicz et al., 2017). The coefficient value should be selected individually for the pelleted material. Usually, the higher value of the compression ratio has a positive effect on the quality of the obtained pellet (Zdanowicz et al., 2016). Most often during sawdust pelleting the dies have holes with diameters $d=6 \mathrm{~mm}$ or $\mathrm{d}=8 \mathrm{~mm}$, which are arranged on the die in such a way that they form a "honeycomb" structure for die blocks with smaller diameters or holes are arranged

Prof.: Faculty of Mechanical Engineering, Koszalin University of Technology, Raclawicka Street 15-17; 75-620 Koszalin; PL, jerzy.chojnacki@tu.koszalin.pl,

** PhD.: Faculty of Mechanical Engineering, Koszalin University of Technology, Raclawicka Street 15-17; 75-620 Koszalin; PL, pawel.kaldunski @tu.koszalin.pl,

*** PhD.: Faculty of Wood Processing Industry in Szczecinek, Koszalin University of Technology, Pilska Street 2; 78-400 Szczecinek; PL, slawomir.nagnajewicz@tu.koszalin.pl,

$\dagger \quad$ PhD.: Faculty of Wood Processing Industry in Szczecinek, Koszalin University of Technology, Pilska Street 2; 78-400 Szczecinek; PL, radoslaw.patyk@tu.koszalin.pl 
radially for dies with larger diameters. The shape of the dies holes differs depending on whether the die block is one-sided or double-sided. The individual work zones in die holes are shown in Figure 2.

a)

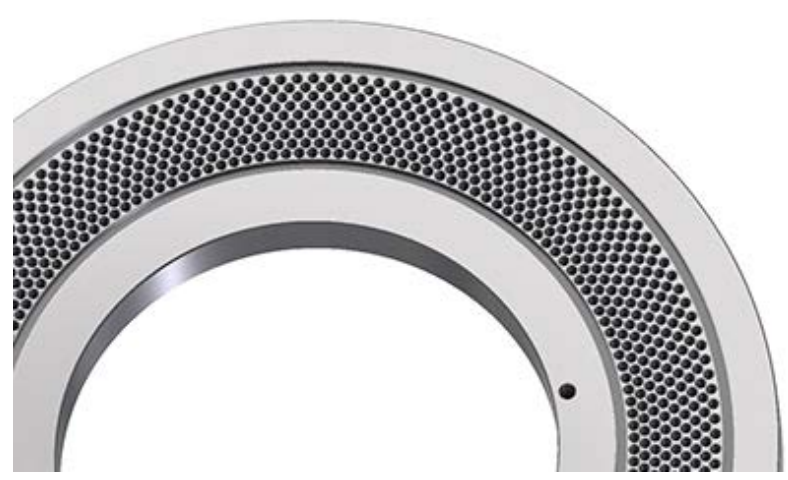

b)

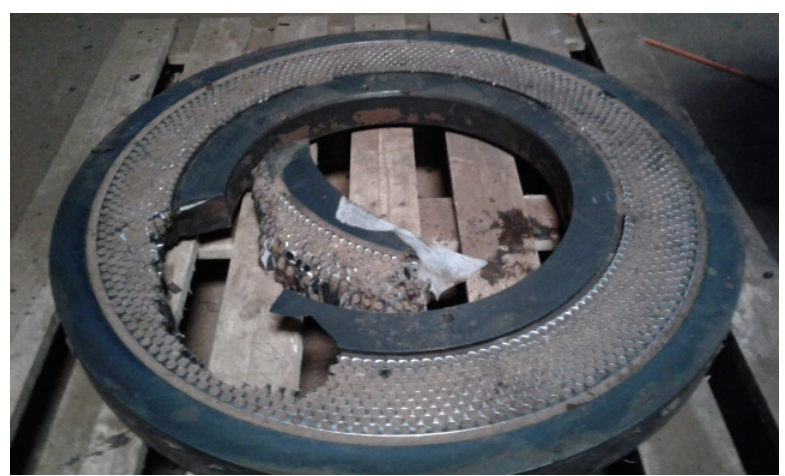

Fig. 1: View of a flat die model (a) and a damaged flat die in the operation process (b). Source: own study.

a) Duble-sided die

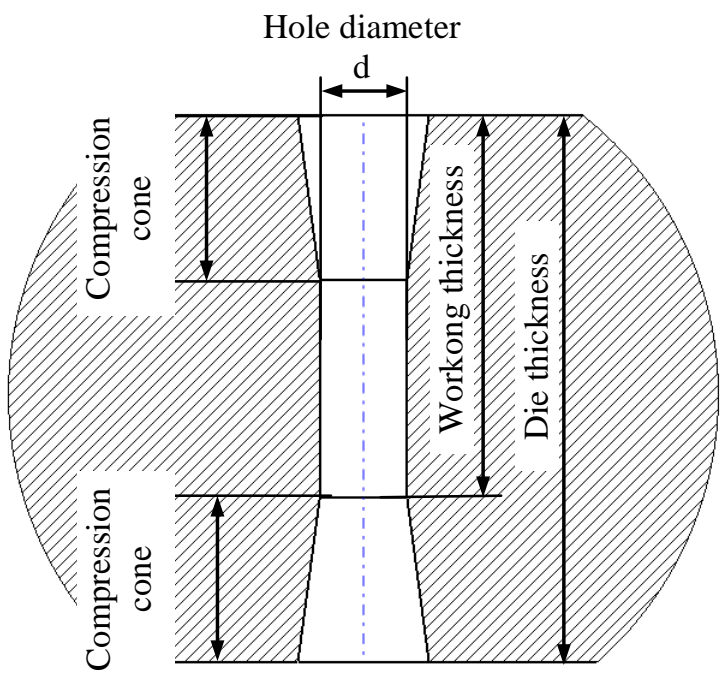

Two-sided compression cone b) Unilateral die

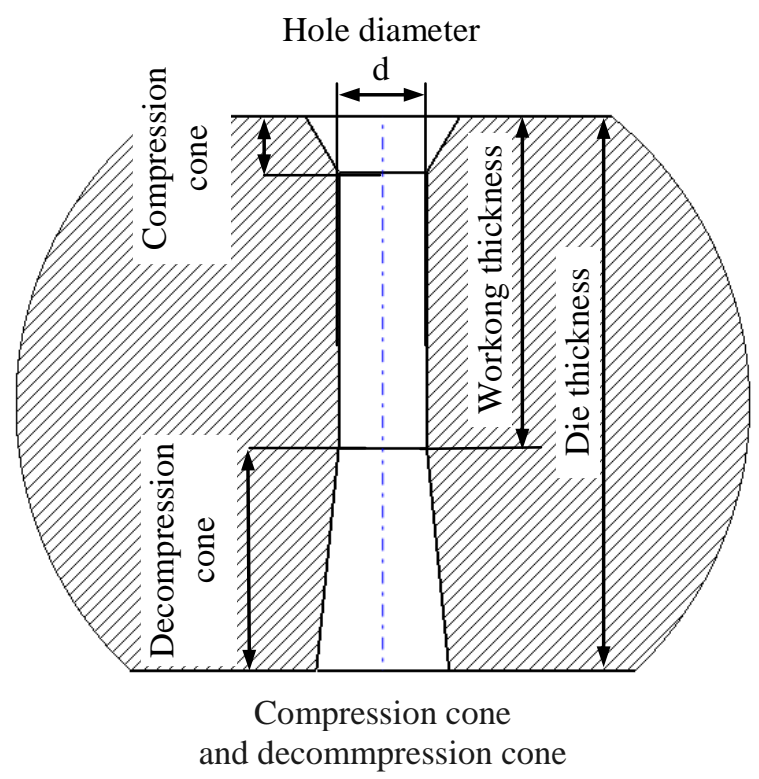

Fig. 2: Hole shapes used in pellet dies for: a) double-sided dies and b) for one-sided dies.

The two basic parameters of the stacking cones are the angle of the cone forming and its depth in the hole. The larger dimensions of each of these elements, the larger is the elementary portion of material pressed through the die at one time, which is associated with an increase in the power demand of the pelletizer. If there are too small compression cones in the die block (the angle of the cone forming and its depth), this may affect to obtaining of pellets with undesirable technological quality (Fiszer, 2009). The selection of appropriate sizes of stacking cones requires a lot of experience and often repeated tests and studies. Due to the fact that experimental studies of the pelleting process are expensive and time-consuming research (high cost of making dies and different properties of pelleted material), other methods of selecting the construction parameters of pellet dies should be sought (Hajft et al., 2012). Therefore, the work dealt with a new approach to the problem - a simulation study of the pelleting process in terms of the obtained states of stress, contact pressures and fatigue strength of the die block disk pellet machine (Bohdal, 2016). Computer simulations were carried out using the Finite Element Method, using the implicit integration method of the equation of motion object (according to Newmark algorithm) (Bohdal, 2012). 


\section{Numerical model of the pelleting process}

The paper deals with numerical investigations of the pelleting process on the disk pellet machine. The type of granulator with drive for compacting rolls and a fixed die was assumed for analysis. In computer simulations (Kulakowska et al., 2014), it was assumed that the one-sided die block is made of perfectly elastic material of the $12 \mathrm{Cr} 1 \mathrm{MoV}$ grade, it was assumed that the Young's modulus is $\mathrm{E}=2.1 \cdot 10^{11} \mathrm{~Pa}$ and Poisson's ratio is $v=0.3$. In the simulations, the influence of thermal phenomena was omitted. The geometric model was discretized on 90135 tetragonal finite elements (153115 nodes). As pellet material, sawdust with the following material parameters was adopted: Young's modulus is $\mathrm{E}=4.4 \mathrm{MPa}$ and Poisson's ratio is $v=0,38$ and the density $\rho=365 \mathrm{~kg} / \mathrm{m}^{3}$. The geometrical model is shown in Figure 3 , where die block diameter equal $\mathrm{D}=600 \mathrm{~mm}$. Holes with diameter $\mathrm{d}=8 \mathrm{~mm}$ on the die are arranged radially, while the angle forming the compression cone is $\alpha=20^{\circ}$ and its depth is $\mathrm{g}=10 \mathrm{~mm}$. At the rollers a force equal $\mathrm{F}=10 \mathrm{kN}$ has been assumed (Kukielka et al., 2012). The die was immobilized on surfaces in accordance with the conditions that occur during exploitation.

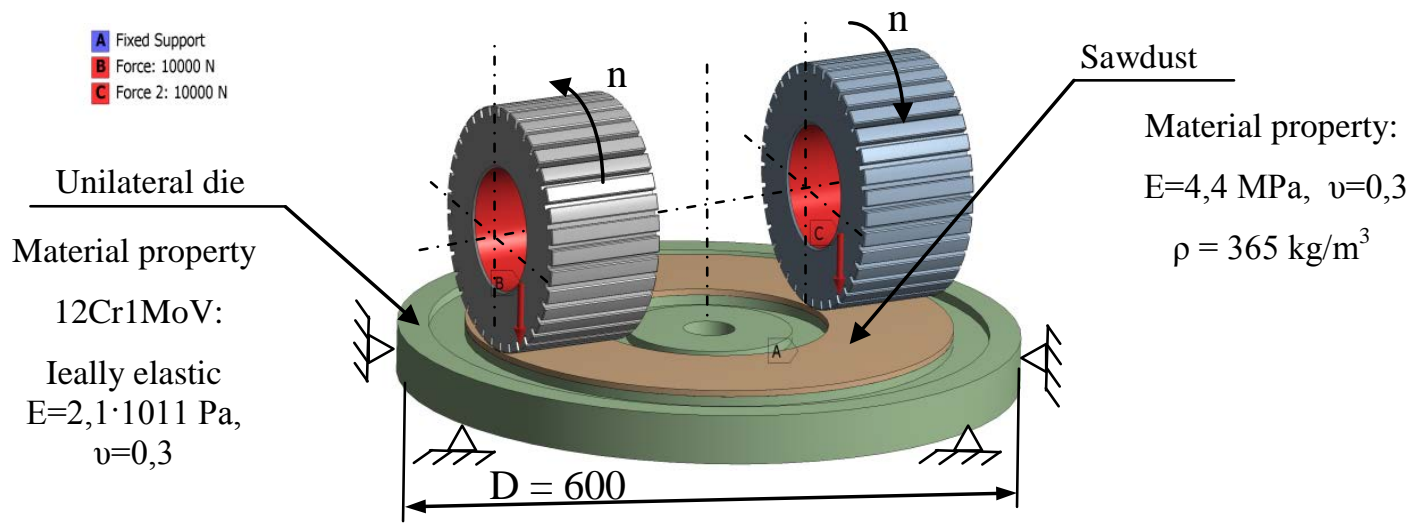

Fig. 3: Geometric model with assumed boundary and initial conditions for the sawdust pelleting process.

After the calculations, the following state of reduced pressures (Figure 4a) and the state of contact pressure (Figure $4 \mathrm{~b}$ ) have been obtained.

a)
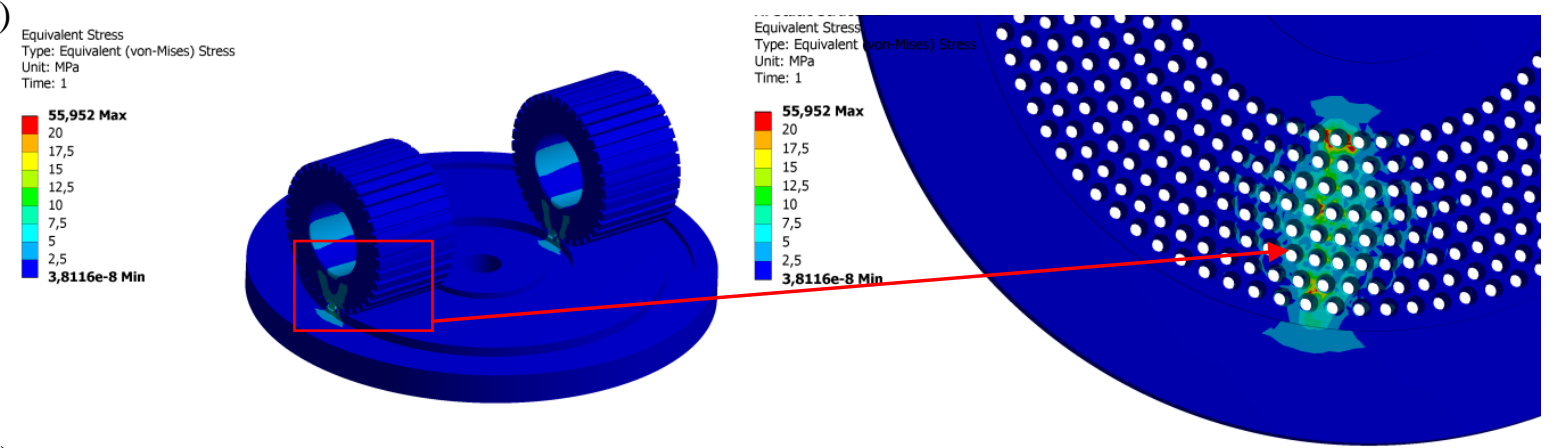

b)
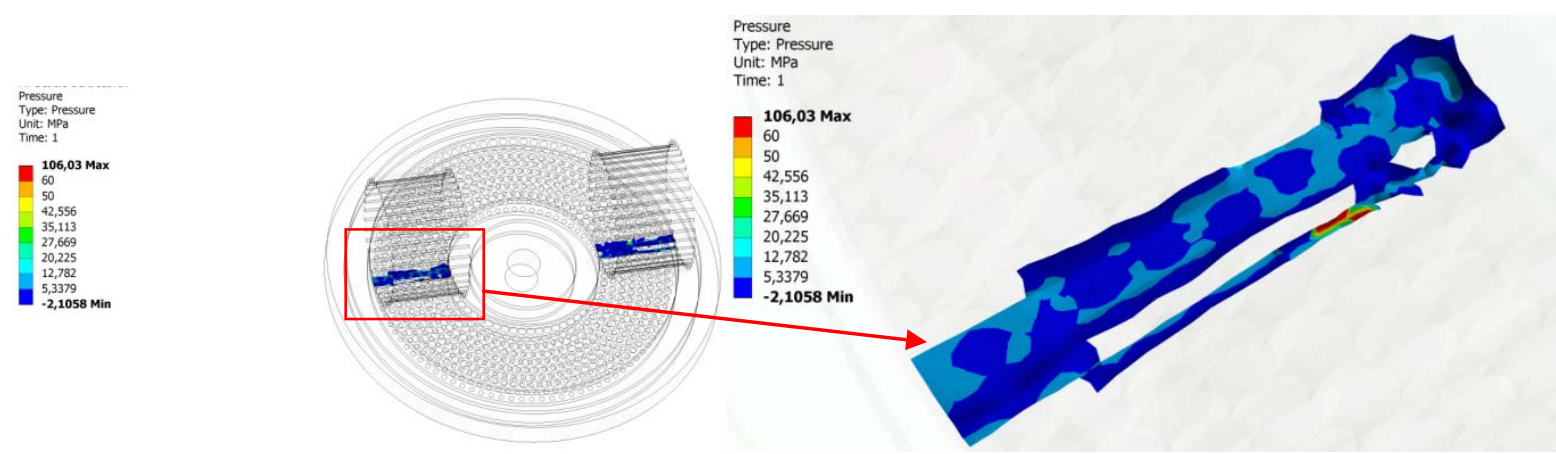

Fig. 4: State of reduced von Misses stress in the die (a) and state of pressure in the contact zone (b) during the sawdust pelleting process. 
Structures subjected to multiple loads not exceeding the permissible loads, may be damaged in the form of an unexpected crack following the specified number of load changes. This kind of exhaustion of the load capacity of material loaded with periodically varying forces is called material fatigue. One of the characteristic features of fatigue cracking is that even in the case of metals having static loads, good plastic properties, the fatigue breakthrough does not show any pronounced plastic deformation at the microscopic scale. Due to the increasing competitiveness in the mechanical industry, fatigue analysis is a must. It was assumed that the die block is affected by unilateral variable loads, it was assumed that the load changes sinusoidally over time. The life results (number of cycles) obtained on the basis of computer simulations are shown in Figure 5. The smallest number of cycles of load changes that the die block will withstand is $\mathrm{n}_{\min }=2.144 \cdot 10^{6}$.

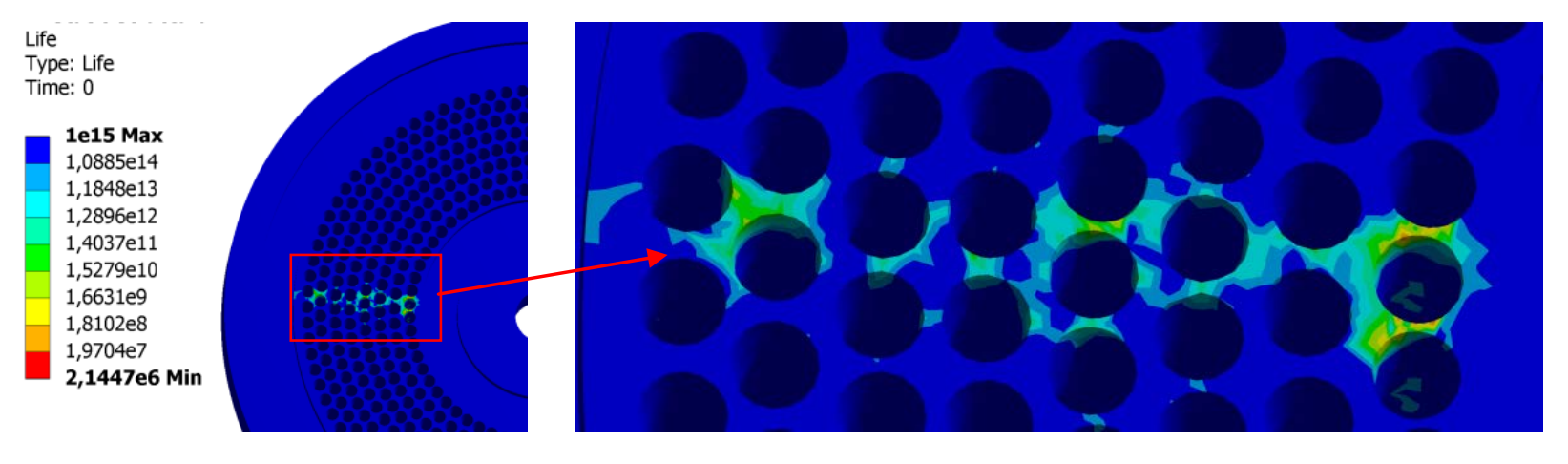

Fig. 5: Life distribution at the die surface (number of cycles of load changes)

\section{Conclusions}

Numerical simulations of the sawdust pelleting process were carried out in the work. The performed analyses are a good foundation for designing of the die blocks. They allow to evaluate the state of stress, pressure in the contact zone and durability of the die block depending on the properties of the pelleted material. On the basis of the proposed method supporting the design of the die blocks, it is possible to carry out analyses for other hole geometries, and as a result, their optimization due to the adopted criteria. The proposed approach will significantly reduce the time of experimental research and their costs. The new (optimal constructions) obtained on this basis will significantly improve the efficiency of the pelleting process.

\section{References}

Bohdal L. (2012) Finite element simulation of 3D sheet metal guillotining using elastic/visco-plastic damage model. Steel Research International. 1419-1422.

Bohdal L. (2016) The application of the smoothed particle hydrodynamics (SPH) method to the simulation and analysis of blanking process, Mechanics Vol 22, No 5, DOI: http://dx.doi.org/10.5755/j01.mech.22.5.13459

Buchely M. F., Colorado H. A. (2016) Failure Analysis of a Pellet-Mill Die, Journal of Failure Analysis and Prevention, 2016) 16:285-292, DOI 10.1007/s11668-016-0085-2.

Fiszer A .(2009) Influence of straw humidity and temperature of briquetting process on the quality of agglomerate, Journal of Research and Applications in Agricultural Engineering, vol. 54(3)

Hejft R, Obidziński S. (2012) The pressure agglomeration of the plant materials - the technological and technical innovations. part 1, Journal of Research and Applications in Agricultural Engineering vol. 57(1)

Kulakowska A., Patyk R., Bohdal L. (2014) Application of burnishing process in creating environmental product, Annual Set The Environment Protection, 16, pp. 323-335.

Kukielka, L.; Geleta, K.; Kukielka, K. (2012) Modelling of initial and boundary problems with geometrical and physical nonlinearity and its application in burnishing processes, Steel Research International, Special Edition, 14th International Conference on Metal Forming: 1375-1378.

Tie-Li Ye, He Li, Liang Wang, and Xiao-Fei Fan (2012) Finite Element Analysis on Biomass Pelletizing Process, Proceedings of the ICCEAE2012, AISC 181, pp. 39-44.

Zdanowicz A., Chojnacki J. (2017) Mechanical properties of pellet from chicken manure mixed with chopped rye straw, Journal of Research and Applications in Agricultural Engineering, Vol. 62(4)

Zdanowicz A., Chojnacki J. (2016) Mobile machines for straw pelleting, Technika Rolnicza Ogrodnicza Lesna. $6 / 2016$ 